\title{
Prediction of 2000 Meters Indoor Rowing Performance Using a 100 Meters Sprint, 60 Second Sprint and 6000 Meter Test
}

\author{
Dede Rohmat Nurjaya*, Amung Ma'mun Agus Rusdiana \\ Prodi Pendidikan Olahraga, Sekolah Pascasarjana \\ Universitas Pendidikan Indonesia \\ Bandung, Indonesia \\ *dede-rohmat-n@upi.edu
}

\begin{abstract}
The purpose of this research is to predict the performance of 2000 meters indoor rowing using 100-meter test, 60 s test and 6000-meter test. The sample used is 22 rowing athletes, consisting of 10 male lightweight athletes, 3 male heavy weight athletes, 7 female light weight athletes and 2 female heavyweight athletes aged around $19 \pm 29$ years old, who joined the Program Indonesia Emas. Participants give written approval before participating in this research. All experimental procedures are approved by the Executive Board of the Indonesian Rowing and Canoeing Association (PB PODSI). The test was performed with a physical test series developed by Danish Rowing, taking a standard of 21 Danish rowers. Rowing athletes participate in a series of physical tests conducted within 4 days, displaying all out performance for specified test types as well as the distance specified using Concept 2 , type $\mathrm{C}$ rowing ergometer. The results of this study is a prediction of 2000 meter power performance based on 100 meter test power performance, 60 second test and 6000 meter test. This study reflects an optimal physiological adaptation for rower performance. Rowers can use the same general training preparations, whether they are open classes or light classes, male or female. Dividing the training according to the endurance curve for each rower. If an oarsman does anaerobic tests poorly, he may have to do more strength training and power exercises. On the other hand, if an oarsman is too strong in relation to his aerobic endurance, he should focus on aerobic training. This research will be useful, because the trainer will get the profile data of each group or athletes that will be a reference for trainers in sorting out and choosing what physiological aspects should be a priority target in planning the exercises.
\end{abstract}

Keywords—performance rowing; indoor rowing; ergometer

\section{INTRODUCTION}

The energy for rowing comes from the aerobic and anaerobic systems (most of the research is done on male elite rowers). It was stated that rowing with a time of 6:43 minutes requires an $84 \%$ aerobic energy system and $16 \%$ anaerobic energy [1]. This is also in line with the statements of Droghetti, Jensen, and Nilsen who found an aerobic contribution of $80 \%$ to $82 \%$, on a 6-minute ergometer test [1]. Research conducted by Fiskerstrand and Seiler explained about VO2Max in athlete elites which increased by $12 \%$ during the training period and conversely the volume of exercises that prioritized anerobics decreased from 23 hours to 7 hours in one month [2]. This shows that the training program and fitness capacity have an impact on aerobic and anaerobic energy production when rowing as far as $2 \mathrm{~km}$. A good level of fitness with a high capacity of $\mathrm{VO} 2 \mathrm{max}$ allows athletes to row during the race without relying heavily on anaerobic systems. The anaerobic system (anaerobic alactacid and anaerobic glycolytic system) contribute greatly at start and towards the finish of a race. When developed properly, the anaerobic system can contribute about 2 minutes of primary energy. Because rowing $1 \mathrm{~km}$ lasts an average of 4 minutes. We can illustrate that the anaerobic contribution to $1 \mathrm{~km}$ races is $50 \%$ to $60 \%$ of total energy. Understanding the physiological profile in a race provides some general information on the importance of the rower's physiological profile when searching for talent. Some physiological characteristics that need to be considered for rowing athletes are as follows:

As explained earlier, anaerobic contribution to energy production in rowing reached $50 \%$ in $1000 \mathrm{~m}$ and a $20 \%$ to $30 \%$ race in the $2,000 \mathrm{~m}$ race. Anaerobic fitness plays an important role at the start and $250 \mathrm{~m}$ towards the finish during the race. The two Anaerobic fitness aspects in the spotlight are peak power and average strength. In recent years' peak power has begun to emerge as a strong predictor of rowing performance. Analysis of data collected from Canadian heavyweight elite athletes showed that strength in VO2max was a predictor.

The average anaerobic power was also found to be strongly associated with rowing performance. Riechman et al. found that the average power of the 30-second ergometer sprint test explained $75.7 \%$ of the variance in the $2000 \mathrm{~m}$ ergometer performance while VO2max only explained $12.1 \%$ [3]. It might seem contradictory that anaerobic variables are predictors of rowing performance that are better than aerobic fitness variables given that rowing is a sport dominated by aerobic abilities. However, the fact that every coach realizes the importance of aerobic fitness in rowing is the most likely explanation for this phenomenon. Because every coach knows that aerobic fitness is very important, there is a greater 
emphasis on training in developing aerobic systems compared to anaerobic.

$2000 \mathrm{~m}$ indoor rowing performance is highly dependent on aerobic and anaerobic functional capacities [4], and the ability to maintain aerobic and anaerobic performance [5]. The energy required for $2000 \mathrm{~m}$ indoor rowing is estimated to be $65 \pm 75 \%$ aerobic and $25 \pm 35 \%$ anaerobic [6]. However, other studies also suggest that anaerobic capacity only explains $10 \pm 20 \%$ of the performance of trained rowers, while aerobic metabolism shows a contribution of $67-88 \%$ [7] and, because rowing performance is highly correlated with maximum oxygen uptake (VO2Max) [8,9], hence maximal oxygen uptake (VO2Max) is an important physiological parameter for rowing rowers. VO2Max is the variable with the largest correlation $(r=0.71)$ with rowing performance compared to other parameter correlations [10]. Cosgrove et al. examined the relationship between performance of $2000 \mathrm{~m}$ indoor rowing and physiological variables at club-level rowers and found that VO2Max showed the highest correlation [11].

Apart from the importance of VO2Max as a determinant of rowing indoor $2000 \mathrm{~m}$ rowing performance, rowing is a power endurance sport [12]. The production of large strengths and the contribution of higher anaerobic metabolism can be done in rowing compared to other endurance sports because rowing is relatively short (ie $\pm 6 \pm 8$ minutes) and requires only the speed and frequency of slow muscle contraction [13], so that it can improve the recovery of anaerobic energy systems. Furthermore, Russell et al. conducted a study using accumulated oxygen deficits as a measure of anaerobic capacity but apparently did not predict the performance of a $2000 \mathrm{~m}$ indoor rowing [14]. Although the accumulation of oxygen deficits consistently shows a high correlation with VO2max, this is not sufficient to predict exercise performance that depends on the measured level of anaerobic strength [7].

Although indoor rowing on an ergometer does not fully require the same skills as rowing on water, research shows that the ergometer simulates the same biomechanical and metabolic rowing as on water [15]. Therefore, ergometers are usually used to measure individual physiological performance variables and become one of the rowing training methods $[5,16]$. Riechman et al. conducted a study by predicting the performance of $2000 \mathrm{~m}$ indoor rowing using $30 \mathrm{~s}$ sprint and maximum oxygen uptake [3]. This study suggests that the method used is able to accurately predict the performance of $2000 \mathrm{~m}$ ergometer rowing on female professional rowers, and the possibility of developing the method by testing more specifically on aerobic and anaerobic. The purpose of this study was to develop a method for predicting rowing performance in indoor rowing through $100 \mathrm{~m}, 60 \mathrm{~s}$ and $6000 \mathrm{~m}$ sprint performance. This study hypothesizes that the $100 \mathrm{~m}, 60$ $\mathrm{s}$ and $6000 \mathrm{~m}$ sprint methods will predict the performance of $2000 \mathrm{~m}$ indoor rowing.

\section{METHOD}

\section{A. Participants}

10 male Lightweight athletes, 3 male Heavyweight athletes, 7 male Lightweight athletes, 2 female Heavyweight athletes aged $19 \pm 29$ years who are members of Program Indonesia Emas Cabang Olahraga Dayung Rowing, participated in this study. All experimental procedures were approved by the Indonesian Rowing Association Executive Board (PB. PODSI).

\section{B. Test Application}

\section{1) The 60-second test}

a) Test preparation: To do this test you need a Concept 2 ergometer and a video camera. Video cameras must be installed to record monitors on the ergometer. Performance monitors on ergometers can be connected to a computer, and you can download data using the program from the manufacturer's website. The ergometer monitor needs to display power per stroke and average power in watts. The ergometer fan should be set at 10 and note the drag factor; the higher the drag factor is, the better it will get. Warm up with steady-state rowing for about 10 minutes. Then stop, drink a little water, and start training yourself. Set up the monitor for 1 minute of work and take a 1 minute break and turn on the video camera. The test can be done without a video camera, but someone needs to record the power output for each hit. The video camera allows you to review this test as much as needed to ensure that you record the right wattage for each stroke.

b) Test application: Start rowing lightly; the monitor must calculate the 1 minute working period. Continues to row when the monitor switches to the rest period. For the last 3 to 5 seconds of the rest period, start some hard strokes by increasing the stroke speed and pulling harder. Once the monitor switches back to the 1 minute work period, the test will turn on and your goal is to draw as many watts as possible for each stroke for the next 60 seconds. You can use the tempo you want as long as you continue rowing with the full slide. Don't row with the rhythm of the race yourself; this is an allout test.

c) Recording the result: To get your test results, you need to analyze the video footage. Replay the 1 minute test section of the video. Record the wattage for each test stroke in the spreadsheet and graph the power for all strokes (watts of all stroke performed) for the 60 -second working period.

\section{2) The 100-meter test}

a) Test preparation: To do this test you need a Concept 2 ergometer and a video camera. Video cameras must be installed to record monitors on the ergometer. Performance monitors on ergometers can be connected to a computer, and you can download data using the program from the manufacturer's website. The ergometer monitor needs to display power per stroke and average power in watts. Set the ergometer fan at 10 and note the drag factor; the higher the drag factor is, the better it will get. Warm up with steady-state rowing for about 10 minutes. Then stop, drink a little water, and start training yourself. Set the monitor to 100 meters and turn on the video camera. The test can be done without a video camera, but someone needs to record the power output for each hit. The video camera allows you to review this test as 
much as needed to ensure that you record the right wattage for each stroke.

b) Test application: Start a few hard strokes by increasing the stroke speed and pulling harder; your goal is to draw as many watts as possible on each stroke of 100 meters. You can use the tempo you want as long as you continue rowing with the full slide. Don't row with the rhythm of the race yourself; this is an all-out test.

c) Recording the result: To get your test results, you need to analyze the video footage. Replay the test section 100 meters from the video. Record the wattage for each test stroke in the spreadsheet and graph the power for all stroke strokes (watts of all stroke performed) for the 100 meters working period.

\section{3) 6000-meter test}

a) Test preparation: To do this test you need a Concept 2 ergometer and a video camera. Video cameras must be installed to record monitors on the ergometer. Performance monitors on ergometers can be connected to a computer, and you can download data using the program from the manufacturer's website. The ergometer monitor needs to display power per stroke and average power in watts. Set the ergometer fan at 10 and note the drag factor; the higher the drag factor is, the better it will get. Warm up with steady-state rowing for about 10 minutes. Then stop, drink a little water, and start training yourself. Set the monitor to 6000 meters and turn on the video camera. The test can be done without a video camera, but someone needs to record the power output for each hit. The video camera allows you to review this test as much as needed to ensure that you record the right wattage for each stroke.

b) Test application: Start a few hard strokes by increasing the stroke speed and pulling harder; your goal is to draw as many watts as possible on each stroke of 6000 meters. You can use the tempo you want as long as you continue rowing with the full slide.

c) Recording the result: To get your test results, you need to analyze the video footage. Replay the 6000 meters test section from the video. Record the wattage for each stroke test in the spreadsheet and graph the power for all stroke strokes (watts of all stroke performed) for 6000 meters of work period.

\section{Statistical Analysis}

Variables that are highly correlated with performance are chosen for the development of regression models. Anthropometric data are not included in the analysis because they are highly correlated with physiological variables of interest and, therefore, interfere with ensuring the independent association of these parameters with performance. The 100 meters' test (maximum power), the 60 second test (anaerobic ability) and the 6000 meters' test (aerobic ability) were hypothesized as predictor variables and submitted to stepwise multiple regression analysis (SPSS 7.0, Chicago, IL, USA). The criteria variable is the performance time of the participants in the $2000 \mathrm{~m}$ race recorded during the indoor championship.

\section{Result Analysis}

Power endurance curve including specific physical performance for overdistance is usually used for quantity training. Each group will have a specific profile.

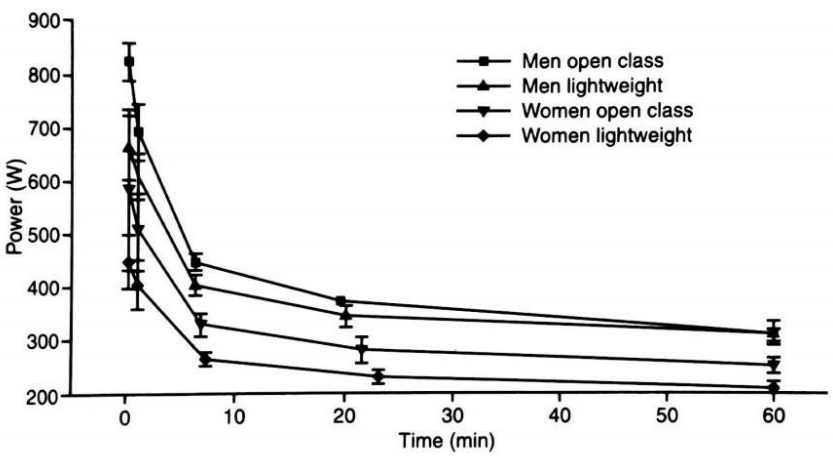

Fig. 1. Power endurance curve.

When power is expressed relative to power for $2 \mathrm{~km}$ of performance and plotted against time, there is no significant difference between open and lightweight classes or between men and women $(p>0.05)[1]$

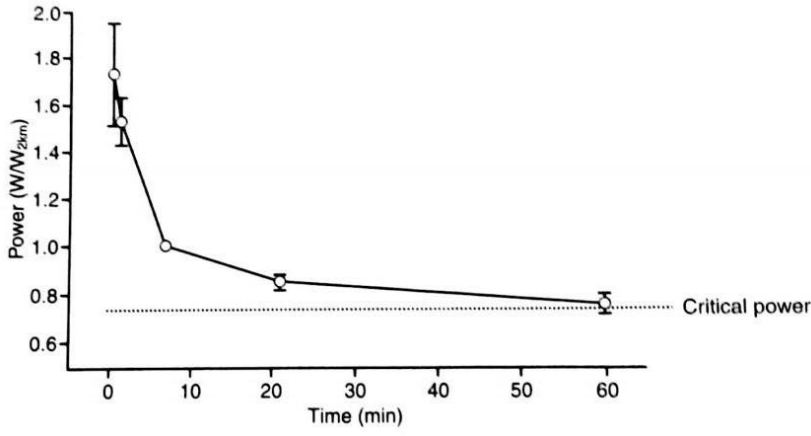

Fig. 2. Relative power - endurance.

Single curves represent men and women in open and light class. We calculate the critical power, or the lower end of the power endurance, to 274 watts or 74 percent of the average power for $2 \mathrm{~km}$ performance (table 2 .)

\section{RESULTS}

On the performance test of 2000 meters, Lightweight man and heavyweight man completed the ergometer test in 394.8401.1 seconds $(394.52 \pm 4.98)$ and $369.8-377.4$ seconds $(373.3$ \pm 3.83 ) respectively. While for Lightweight women and heavyweight women, the results of the time record were 448 477 seconds $(458 \pm 9.05)$ and 429 - 436 seconds $(433 \pm 4.24)$ in that order. The anthropometrics from participants are presented in table 1. Anthropometrics showed a significant correlation in leg length (0.697) in the lightweight man class of 2000 meters. Whereas other anthropometric data showed no correlation. There is no correlation in the anthropometrics found in the results of Lightweight women and heavyweight man, however there was a significant correlation across anthropometrics to the performance of the 2000 meters time record in the Heavyweight women. Data is presented in table 1. 
The results of power (watts) on the 60-second test for Lightweight man (555.9 \pm 33.83), Lightweight Women (360 \pm 23.72), Heavyweight man (680.66 \pm 56.04), Heavyweight Woman $(411.5 \pm 19.09)$ were presented to power (watts) on the performance of 2000 meters of each class. Table 2 showed the results of the power on the 60 -second test. Sorted from the largest to the smallest values are Heavyweight man, Lightweight man, Heavyweight woman, and lightweight woman. However, the percentage of power of 60 seconds with a 2000 meters' performance test that is used as a reference in each class from the largest to the smallest values is Heavyweight Man, Lightweight Woman, Lightweight Man, and Heavy Weight Women.

TABLE I. DESCRIPTIVE AND CORRELATION OF ANTHROPOMETRIC TO 2000 Meter Performance ( $=13 ;$ MEAN \pm S)

\begin{tabular}{|c|c|c|}
\hline Variabel & Mean $\pm s$ & $\mathbf{r}(2000 \mathrm{~m})$ \\
\hline \multicolumn{3}{|c|}{ Lightweight men $(n=10)$} \\
\hline Tinggi Badan $(\mathrm{cm})$ & $177.8 \pm 3.04$ & 0.529 \\
\hline Berat Badan (kg) & $72.37 \pm 1.58$ & -0.497 \\
\hline Panjang Lengan $(\mathrm{cm})$ & $186.05 \pm 4.69$ & 0.353 \\
\hline Tinggi Duduk $(\mathrm{cm})$ & $91.75 \pm 1.37$ & 0.456 \\
\hline Panjang Tungkai $(\mathrm{cm})$ & $108.25 \pm 2.65$ & $0.697^{*}$ \\
\hline Lebar Bahu $(\mathrm{cm})$ & $46.4 \pm 2.22$ & -0.586 \\
\hline Waktu 2000m (s) & $394.52 \pm 4.98$ & \\
\hline \multicolumn{3}{|c|}{ Lighweight women $(n=7)$} \\
\hline Tinggi Badan $(\mathrm{cm})$ & $170.28 \pm 2.05$ & 0.188 \\
\hline Berat Badan $(\mathrm{kg})$ & $60.41 \pm 1.83$ & 0.343 \\
\hline Panjang Lengan $(\mathrm{cm})$ & $172.5 \pm 4.33$ & -0.261 \\
\hline Tinggi Duduk $(\mathrm{cm})$ & $87.14 \pm 2.34$ & -0.047 \\
\hline Panjang Tungkai $(\mathrm{cm})$ & $102.71 \pm 1.11$ & -0.281 \\
\hline Lebar Bahu (cm) & $39.28 \pm 2.13$ & -0.422 \\
\hline Waktu 2000m (s) & $458 \pm 9.05$ & \\
\hline \multicolumn{3}{|c|}{ heavyweight men $(n=3)$} \\
\hline Tinggi Badan $(\mathrm{cm})$ & $188.33 \pm 4.50$ & 0.311 \\
\hline Berat Badan (kg) & $86.2 \pm 3.16$ & -0.941 \\
\hline Panjang Lengan $(\mathrm{cm})$ & $192.3 \pm 3.51$ & 0.294 \\
\hline Tinggi Duduk $(\mathrm{cm})$ & $96.3 \pm 3.51$ & 0.294 \\
\hline Panjang Tungkai $(\mathrm{cm})$ & $113.3 \pm 2.88$ & 0.786 \\
\hline Lebar Bahu (cm) & $49.0 \pm 1.00$ & -0.990 \\
\hline Waktu 2000m (s) & $373.3 \pm 3.83$ & \\
\hline \multicolumn{3}{|c|}{ heavyweight women $(n=2)$} \\
\hline Tinggi Badan $(\mathrm{cm})$ & $172 \pm 2.82$ & $1.000^{*}$ \\
\hline Berat Badan $(\mathrm{kg})$ & $72.35 \pm 1.76$ & $1.000^{*}$ \\
\hline Panjang Lengan $(\mathrm{cm})$ & $180.25 \pm 6.71$ & $1.000^{*}$ \\
\hline Tinggi Duduk $(\mathrm{cm})$ & $89.25 \pm 3.18$ & $1.000^{*}$ \\
\hline Panjang Tungkai $(\mathrm{cm})$ & $105.5 \pm 0$ & $1.000^{*}$ \\
\hline Lebar Bahu (cm) & $41.5 \pm 0.7$ & $1.000^{*}$ \\
\hline Waktu 2000m (s) & $433 \pm 4.24$ & \\
\hline
\end{tabular}

It can be seen in table 2 that each power produced for each class when sorted from the largest to the smallest value is the same; Heavyweight man, Lightweight man, Heavyweight woman, and lightweight woman. However, as a percentage of the performance of the 2000 meters test is used as a reference, the results are varied. Figure 1 shows the curve of the average power to the time of each test.
TABLE II. TEST SERIES AND REFERENCE VALUE

\begin{tabular}{|c|l|l|}
\hline \multicolumn{1}{|c|}{ Test Series } & $\begin{array}{c}\text { Power (watt) } \\
\text { mean } \pm \mathbf{s}\end{array}$ & $\begin{array}{c}\text { Reference } \\
\text { Values (\%) }\end{array}$ \\
\hline $\begin{array}{c}\text { Lightweight man } \\
(\boldsymbol{n}=\mathbf{1 0})\end{array}$ & & \\
\hline 60 detik & $555.9 \pm 33.83$ & $152 \pm 9$ \\
\hline 100 meter & $668.3 \pm 67.98$ & $183 \pm 17$ \\
\hline 2000 meter & $365.3 \pm 13.8$ & 100 (defined) \\
\hline 6000 meter & $281 \pm 14.4$ & $76 \pm 2$ \\
\hline $\begin{array}{c}\text { Lightweight } \\
\text { women }(\boldsymbol{n}=7)\end{array}$ & & \\
\hline 60 detik & $360 \pm 23.72$ & $154 \pm 6$ \\
\hline 100 meter & $414.71 \pm 21.84$ & $178 \pm 12$ \\
\hline 2000 meter & $232.71 \pm 12.88$ & 100 (defined) \\
\hline 6000 meter & $188.85 \pm 13.14$ & $81 \pm 4$ \\
\hline $\begin{array}{c}\text { Heavyweight } \\
\text { man }(\boldsymbol{n}=3)\end{array}$ & & \\
\hline 60 detik & $680.66 \pm 56.04$ & $157 \pm 11$ \\
\hline 100 meter & $851.00 \pm 65.48$ & $197 \pm 15$ \\
\hline 2000 meter & $431.66 \pm 13.65$ & 100 (defined) \\
\hline 6000 meter & $317.66 \pm 20.5$ & $73 \pm 2$ \\
\hline $\begin{array}{c}\text { Heavyweight } \\
\text { women }(\boldsymbol{n}=2)\end{array}$ & & \\
\hline 60 detik & $411.5 \pm 19.09$ & $149 \pm 11$ \\
\hline 100 meter & $457 \pm 21.21$ & $165 \pm 13$ \\
\hline 2000 meter & $276.5 \pm 9.19$ & 100 (defined) \\
\hline 6000 meter & $224.5 \pm 0.7$ & $81 \pm 2$ \\
\hline
\end{tabular}

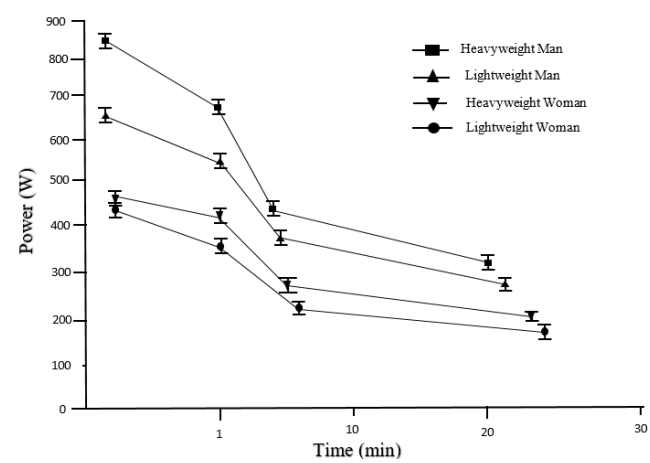

Fig. 3. Anaerobic power.

TABLE III. THE COMPARISON BETWEen ACTUAL AND IDEAL VALUE

\begin{tabular}{|l|l|l|}
\hline \multicolumn{1}{|c|}{ Test } & \multicolumn{1}{c|}{ Actual } & Ideal \\
\hline 60 detik & & \\
\hline 100 meter & $152 \pm 9$ & $153 \pm 10$ \\
\hline 2000 meter & $183 \pm 17$ & $173 \pm 22$ \\
\hline 6000 meter & $100($ defined $)$ & \\
\hline Lightweight women $(\boldsymbol{n}=7)$ & $76 \pm 2$ & $86 \pm 3$ \\
\hline 60 detik & & \\
\hline 100 meter & $154 \pm 6$ & $153 \pm 10$ \\
\hline 2000 meter & $178 \pm 12$ & $173 \pm 22$ \\
\hline 6000 meter & $100($ defined $)$ & \\
\hline Heavyweight man $(\boldsymbol{n}=3)$ & $81 \pm 4$ & $86 \pm 3$ \\
\hline 60 detik & & \\
\hline 100 meter & $157 \pm 11$ & $153 \pm 10$ \\
\hline 2000 meter & $197 \pm 15$ & $173 \pm 22$ \\
\hline 6000 meter & $100($ defined $)$ & \\
\hline Heavyweight women $(\boldsymbol{n}=2)$ & $73 \pm 2$ & $86 \pm 3$ \\
\hline 60 detik & $149 \pm 11$ & \\
\hline 100 meter & $165 \pm 13$ & $173 \pm 10$ \\
\hline 2000 meter & $100($ defined $)$ & \\
\hline 6000 meter & $81 \pm 2$ & $86 \pm 3$ \\
\hline & & \\
\hline
\end{tabular}




\section{DISCUSSION}

As explained earlier, the aerobic system provides the most energy for rowing performance. The main indicator of aerobic fitness for rowers is the aerobic threshold, anaerobic threshold, and VO2Max. Figure 4 shows the relative position of each point based on the lactate.

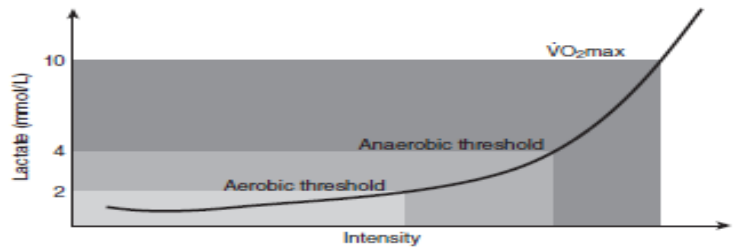

Fig. 4. Aerobic threshold, anaerobic threshold, and VO2max.

The aerobic threshold is defined as the threshold for energy metabolism where the concentration of lactate in the blood increases clearly from the level of rest [17] and also the threshold where most muscle fibers work aerobically. In the range of lactate, the magnitude of this point is at $2 \mathrm{mmol}$ lactate in the blood [18]. Aerobic threshold occurs because of changes in muscle fibers that work or contract during activity [19], when doing exercise with low intensity the muscles will contract slowly and as the intensity increases, more and more pulses of muscle fibers contract or activate. The aerobic threshold did not play an important role during the rowing race. However, this is an important marker when undergoing exercise intensity

To analyze the data, we need to understand the relationship of the actual value in table 3 with the relative position of the physiological points of each point based on the figure in Figure 2. Figure 2 shows the relationship between physiological points. Each of these physiological points can only approach at the point where we stop seeing progress. For example, in the Lightweight Man category, if the 1 minute test threshold to find out anaerobic capacity has reached $183 \%$ compared to the ideal target of $173 \%$, it will be difficult to increase it at a higher percentage. This doesn't mean we can't get it up to $190 \%$, but it takes years to do it. we might get a better race result by focusing our training in the area of 6000 meters (aerobic capacity) which has only reached $76 \%$ compared to the ideal target of $86 \%$.

From the other results, we see that the 100 meters test and 100 meter (anaerobic capacity) on the Heavyweight Man are the percentage of peak strength that exceed the expected result, $197 \%$ compared to $173 \%$ ideal. This athlete does not need to focus on improving abilities in this area. To improve the performance of the 2000 meter race, it would be better to increase the ability of the 6000 meter test in which the achievement is still at 73 percent compared to the ideal target of 86 percent, and so do the athletes in the Lightweight Man category.

Finally, we can also see that aerobic capacity, as measured by the 6000 meters test in the group of Heavyweight Man and Lightweight Man athletes, was in the range of $73 \%-76 \%$, lower by $10 \%-13 \%$ than the ideal target of $86 \%$. This shows the need for more low-intensity yet long-duration exercises.
Once we have the data and have determined what we need to train, we can set training priorities. Our first priority is to train the area with the biggest percentage difference between our athlete's score and ideal. In our example, this is the aerobic ability of the male group that is $10 \%-13 \%$ away from the expected result. The second priority is the anaerobic threshold. Fortunately, low intensity training to improve aerobic abilities will bring a slight increase in anaerobic abilities.

\section{CONCLUSION}

Data from this study reflect optimal adaptation for rower performance. Rowers can use the same general training preparation whether they are open class or light class, male or female. Divide the training according to the endurance curve for each rower. If a rower performs anaerobic tests poorly, he may need to do more strength training and power training. On the other hand, if a rower is too strong in his aerobic endurance, he must focus on aerobic training. Quality of Exercise [1].

A1. Muscle power training at 100 meters test intensity.

A2. Anaerobic capacity training at a test intensity of 60 seconds.

B. Aerobic exercise power with an intensity less than or close to the intensity of the test capability of 2 kilometers.

C. Aerobic exercise capacity with a slightly lower intensity than the test intensity of 6 kilometers but higher than the test intensity of 60 seconds.

D. Aerobic endurance training has a lower intensity than the 60 minute test intensity

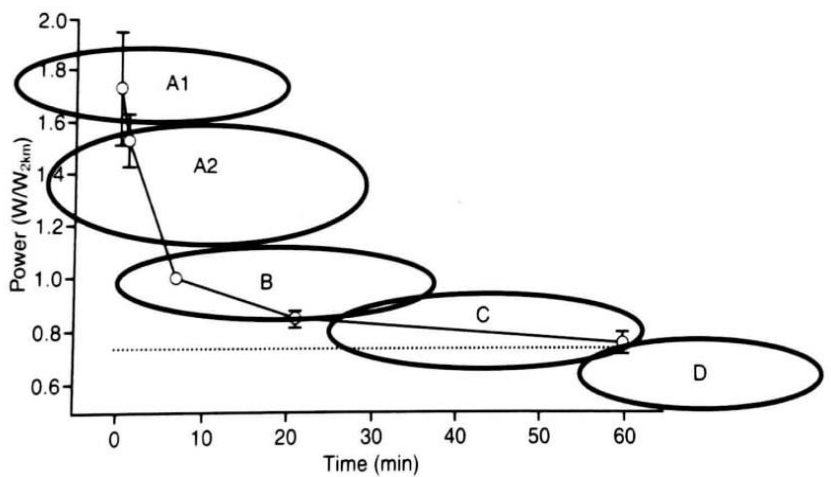

Fig. 5. Relative power at various training intensities is related to the power of the 2 kilometer test results.

\section{REFERENCES}

[1] N.V. Faster, 2nd ed. Human Kinetics, 2011.

[2] A. Fiskerstrand and K.S. Seiler, "Training and performance characteristics among Norwegian International Rowers 1970-2001," Scand J Med Sci Sport, vol. 14, no. 5, pp. 303-10, 2004.

[3] S.E. Riechman, R.F. Zoeller, G. Balasekaran, F.L. Goss and R.J. Robertson, "Prediction of $2000 \mathrm{~m}$ indoor rowing performance using a 30 $\mathrm{s}$ sprint and maximal oxygen uptake Prediction of $2000 \mathrm{~m}$ indoor rowing performance using a $30 \mathrm{~s}$ sprint and maximal oxygen uptake," J Sports Sci., vol. 20, no. 9, pp. 681-7, 2002 
[4] C.J. Huang, T.W. Nesser and J.E. Edwards, "Journal of Exercise Physiology online Strength And Power Determinants Of Rowing," J Am Soc Exerc Physiol, vol. 10, no. 4, pp. 43-50, 2007.

[5] F. Hagerman and M. Hagerman, A Comparison of Energy Output and Input among Elite Rowers, p. 267-83, 1990.

[6] F.C. Hagerman, M.C. Connors, J.A. Gault, G.R. Hagerman and W.J. Polinski, "Energy expenditure during simulated rowing," J Appl Physiol, vol. 45, no. 1, pp. 87-93, 1978.

[7] L.P. Pripstein, E.C. Rhodes, D.C. McKenzie and K.D. Coutts, "Aerobic and anaerobic energy during a 2-km race simulation in female rowers," Eur J Appl Physiol Occup Physiol, vol. 79, no. 6, pp. 491-4, 1999.

[8] S.A. Ingham, G.P. Whyte, K. Jones and A.M. Nevill, "Determinants of $2,000 \mathrm{~m}$ rowing ergometer performance in elite rowers," Eur $\mathbf{J}$ Appl Physiol, vol. 88, no. 3, 243-6, 2002.

[9] S. Boegman and C.E. Dziedzic, "Nutrition and Supplements for Elite Open-Weight Rowing," Curr Sports Med Rep., vol. 15, no. 4, 252-61, 2016.

[10] J.F. Kramer, A Leger, D.H. Paterson and A. Morrow, Rowing Performance and Selected Descriptive, Field, and Laboratory Variables, pp. 174-84, 1994

[11] M.J. Cosgrove, J. Wilson, D. Watt and S.F. Grant, "The relationship between selected physiological variables of rowers and rowing performance as determined by a 2000 m ergometer test," J Sports Sci., vol. 17 , no. $11,845-52,2010$.

[12] J. Peltonen and $\mathrm{H}$ Rusko, "Interrelations between power, force production and energy metabolism in maximal leg work using a modified rowing ergometer Interrelations between power, force production and energy metabolism in maximal leg work using a modified rowing ergometer, pp. 233-40, 1993.

[13] N.H. Secher, "Physiological and Biomechanical Aspects of Rowing Implications for Training," vol. 15, no. I, pp. 24-42, 1993.

[14] A.P. Russell, Le Rossignol P.F. and Sparrow W.A, "Prediction of elite schoolboy 2000-m rowing ergometer performance from metabolic anthropometric and strength variables," J Sports Sci., vol. 16, no. 8, 749-54, 1998 .

[15] D.H. Lamb, "A kinematic comparison of ergometer and on-wate rowing," vol. 17, no. 3, 1989.

[16] J. Bouckaert, J.L. Pannier and J. Vrijens, "Cardiorespiratory response to bicycle and rowing ergometer exercise in oarsmen," Eur J Appl Physiol Occup Physiol., vol. 51, no. 1, 51, 1983.

[17] S. Aunola and H. Rusko, "Aerobic and anaerobic thresholds determined from venous lactate or from ventilation and gas exchange in relation to muscle fiber composition,/ Seuils aerobie et anaerobie determines par dosage veineux des lactates ou a partir des echanges gazeux en relat," Int J Sports Med, vol. 7, no. 3, pp. 161, 1986.

[18] J.S. Skinner and T.H. McLellan, "The Transition from Aerobic to Anaerobic Metabolism," Res Q Exerc Sport., vol. 51, no. 1, pp. 234-48, 1980

[19] E. Henneman, "Relation between Size of Neurons and Their Susceptibility to Discharge," vol. 126 , no. 3287, 1345-7, 1957. 